\title{
Biodiesel Production from Castor Oil by Using Calcium Oxide Derived from Mud Clam Shell
}

\author{
S. Ismail, ${ }^{1}$ A. S. Ahmed, ${ }^{2}$ Reddy Anr, ${ }^{2}$ and S. Hamdan ${ }^{2}$ \\ ${ }^{1}$ Department of Chemical Engineering, Faculty of Engineering, Universiti Malaysia Sarawak (UNIMAS), \\ 94300 Kota Samarahan, Sarawak, Malaysia \\ ${ }^{2}$ Department of Mechanical Engineering, Faculty of Engineering, Universiti Malaysia Sarawak (UNIMAS), \\ 94300 Kota Samarahan, Sarawak, Malaysia
}

Correspondence should be addressed to S. Ismail; 24025@siswa.unimas.my

Received 2 December 2015; Accepted 10 April 2016

Academic Editor: Abdurrahman Saydut

Copyright (C) 2016 S. Ismail et al. This is an open access article distributed under the Creative Commons Attribution License, which permits unrestricted use, distribution, and reproduction in any medium, provided the original work is properly cited.

\begin{abstract}
The catalytic potential of calcium oxide synthesized from mud clam shell as a heterogeneous catalyst for biodiesel production was studied. The mud clam shell calcium oxide was characterized using particle size analyzer, Fourier transform infrared spectroscopy, scanning electron microscopy, and BET gas sorption analyzer. The catalyst performance of mud clam shell calcium oxide was studied in the transesterification of castor oil as biodiesel. Catalyst characterization and transesterification study results of synthesized catalyst proved the efficiency of the natural derived catalyst for biodiesel production. A highest biodiesel yield of $96.7 \%$ was obtained at optimal parameters such as $1: 14$ oil-to-methanol molar ratio, $3 \% \mathrm{w} / \mathrm{w}$ catalyst concentration, $60^{\circ} \mathrm{C}$ reaction temperature, and 2-hour reaction time. Catalyst reusability test shows that the synthesized calcium oxide from mud clam shell is reusable up to 5 times.
\end{abstract}

\section{Introduction}

The depletion of fossil fuels and increasing demand of conventional energy globally had been the main concern of scientists nowadays. A continuous supply of energy is vital to support the human activities such as industrialization, transportation, and agriculture. As the conventional energy sources are limited, there is a need to generate an alternative, nonconventional energy to support the civilization.

Biodiesel is one of the promising biofuels to replace fossil fuels as a primary energy source for machineries and vehicles [1]. Biodiesel has many important technical advantages over conventional diesel, such as inherent lubricity, low toxicity, derivation from a renewable and domestic feedstock, superior flash point and biodegradability, negligible sulfur content, and lower exhaust emissions [2].

The homogeneous catalyzed transesterification of vegetable oil for biodiesel production possesses some drawbacks such as saponification of the oil, impossibility of catalyst recovery, and limitation in establishing a continuous process [3]. In contrast, the solid catalysts could easily be separated from the reaction mixture by filtration and reused [4]. Heterogeneous base catalysts eliminate the need for the neutralization of homogeneous base catalysts with acids and the removal of water in the commercial production of biodiesel, thereby lowering its production cost [5].

Among the heterogeneous catalysts, calcium oxide has derived researchers attention because it is a cheap and abundantly available in the nature as a limestone and also from sea shells in the form of calcium carbonate, $\mathrm{CaCO}_{3}$.

Calcium oxide can be reused up to 3 times in transesterification reaction which made it an economic catalyst. As the calcium oxide was derived from the natural source, it is environmentally friendly and causes no harm to the ecosystem. Thus, calcium oxide was suitable to be used in large scale production of biodiesel for commercial purpose as it needs no posttreatment prior to its disposal to the environment [6].

Castor oil had its own advantages as one of the promising sources of feedstock for biodiesel production despite having high viscosity compared to other vegetable oils. Castor oil does not contain sulfur; it has greater cetane number which indicates a better quality of ignition and more oxygen content 
TABLE 1: Fatty acids composition of Malaysian castor seed oil [34].

\begin{tabular}{lc}
\hline Fatty acid composition & Percentage (\%) \\
\hline Palmitic, C16:0 & 1.3 \\
Stearic, C18:0 & 1.2 \\
Oleic, C18:1 & 5.5 \\
Linoleic, C18:2 & 7.3 \\
Linolenic, C18:13 & 0.5 \\
Ricinoleic, C18:1 & 84.2 \\
\hline
\end{tabular}

which promote more complete combustion [7]. Castor oil has improved lubricity over other oils with similar carbon chainlength fatty acids. The hydroxylated fatty acids of ricinoleic acid in castor oil impart it better performance as lubricity enhancer than other common vegetable oil esters [8]. Castor biodiesels have a very low cloud point and pour point compared to other biodiesels which made it a best fuel for cold weather. The cloud point and pour point of castor biodiesel were -23 and -45 [9]. Castor oil is distinguished by its high content of ricinoleic acid. No other vegetable oil contains such a high proportion of fatty hydroxyacids. Table 1 shows the fatty acid compositions of castor oil from Malaysian breed.

Several studies had been reported on transesterification of castor oil by using different types of homogeneous and heterogeneous catalyst. Panwar et al. [10] carried the transesterification of castor oil with alkaline catalyst which produces $95.8 \%$ biodiesel yield. Jeong and Park [11] conducted experiments using response surface methodology (RSM) to identify the optimal reaction factors for a biodiesel production using castor oil as a feedstock and potassium hydroxide $(\mathrm{KOH})$ as a catalyst. An optimum biodiesel yield of $92 \%$ achieved for reaction factors: reaction temperature, $35.5^{\circ} \mathrm{C}$; oil-to-methanol molar ratio, $1: 8.24$; catalyst concentration, $1.45 \mathrm{wt} . \%$; and reaction time, $40 \mathrm{~min}$. Nurdin et al. [12] study the transesterification of castor oil using calcined mussel shell as a heterogeneous catalyst. 91.17\% of biodiesel yield was obtained with catalyst loading of $2 \mathrm{w} / \mathrm{w} \%$, time of $3 \mathrm{~h}$, temperature of $60^{\circ} \mathrm{C}$, and methanol-to-oil ratio of $6: 1$. Sánchez-Cantú et al. [13] study the transesterification of castor oil using hydrated lime with different reaction variables such as reaction time and temperature, catalyst loading, and ratio of methanol to oil. The transesterification study successfully yielded biodiesel up to $100 \%$.

In this study, calcium oxide synthesized from the mud clam shell was being used as a heterogeneous catalyst for transesterification of castor oil. The physical and chemical properties of the synthesized catalyst such as microstructure, particle surface area, and infrared absorption patterns were studied. The optimum parameters for transesterification of castor oil such as reaction time, temperature, molar ratio of oil to the methanol, and catalyst concentration were investigated to obtain the highest yield of biodiesel.

\section{Experimental Procedure}

2.1. Crude Castor Oil Preparation. The crude castor oil was extracted from the castor bean by using Soxhlet extraction with hexane as a solvent. The crude castor oil was then degummed with aqueous sulfuric acid to remove gum content of the oil as described by Akpan et al. [14]. The castor oil was then pretreated with acid esterification to reduce the free fatty acid contents of the oil to less than $0.5 \%$ [15]. The pretreated castor oil was ready to be used for biodiesel production.

2.2. Synthesis of Calcium Oxide from Mud Clam Shell. The calcium oxide catalyst used in this study was synthesized from mud clam shell. The mud clam shells were collected from local supplier. The mud clam shell was washed with $1 \%$ aqueous solution of sulfuric acid to remove dirt and stain on the shell surface. The shell was then grinded to powder size using cutting-grinding head (MF 10.1, IKA, Germany). The mud clam shell powder was then treated following hydrothermal treatment as suggested by Yoosuk et al. [16]. The shell powder was thermally decomposed in furnace at $800^{\circ} \mathrm{C}$ for 3 hours. The shell was then refluxed in distilled for 24 hours. The sample was then filtered, oven-dried at $120^{\circ} \mathrm{C}$, and recalcined at $900^{\circ} \mathrm{C}$ for 2 hours using Humboldt muffle furnace (model: $\mathrm{H}-30200)$ to produce fine calcium oxide.

The calcium oxide was then kept in a sealed container to prevent contamination of carbonates and hydroxides. As a reference catalyst, commercial calcium oxide of laboratory grade (Brand: J. T. Bakers) was calcined at $900^{\circ} \mathrm{C}$ for 2 hours to remove any contamination of atmospheric carbonates and hydroxides.

2.3. Characterization of Mud Clam Shell Catalyst. The Fourier transform infrared spectroscopy analysis of calcium carbonate and calcium oxide from mud clam shell was carried out using Shimadzu Iraffinity-1 Spectrophotometer in the region of $4000-600 \mathrm{~cm}^{-1}$. The morphological properties of calcium carbonate and calcium oxide from mud clam shell and commercial calcium oxide were being studied using a scanning electron microscope (SEM, JSM-6390LA JEOL Co. Ltd., Japan) at 10000x magnification at an accelerating voltage of $15 \mathrm{kV}$. Particle size distribution of the calcium oxide from mud clam shell and commercial calcium oxide was analyzed using a particle size analyzer (CILAS-1090).

The textural features of calcium oxide from mud clam shell and commercial calcium oxide were studied by $\mathrm{N}_{2}$ adsorption/desorption method using an automated gas sorption analyzer (Quantachrome Instruments). Degassing of catalyst before the nitrogen sorption measurement was conducted under vacuum condition for $12 \mathrm{~h}$ at a temperature of $200^{\circ} \mathrm{C}$. The specific surface area was calculated by using the Brunauer-Emmett-Teller (BET) equation. The average pore radius and total pore volume were determined by using the Barrett-Joyner-Halenda (BJH) method.

2.4. Mud Clam Shell Catalyzed Transesterification of Castor Oil. The calcium oxide from mud clam shell was used as a catalyst in the transesterification study of castor oil. Transesterification of castor oil was carried out in a three-neck round-bottom flask equipped with condenser, thermometer, and magnetic heating mantle. Magnetic stirrer was being used to stir the solution throughout the reaction. 


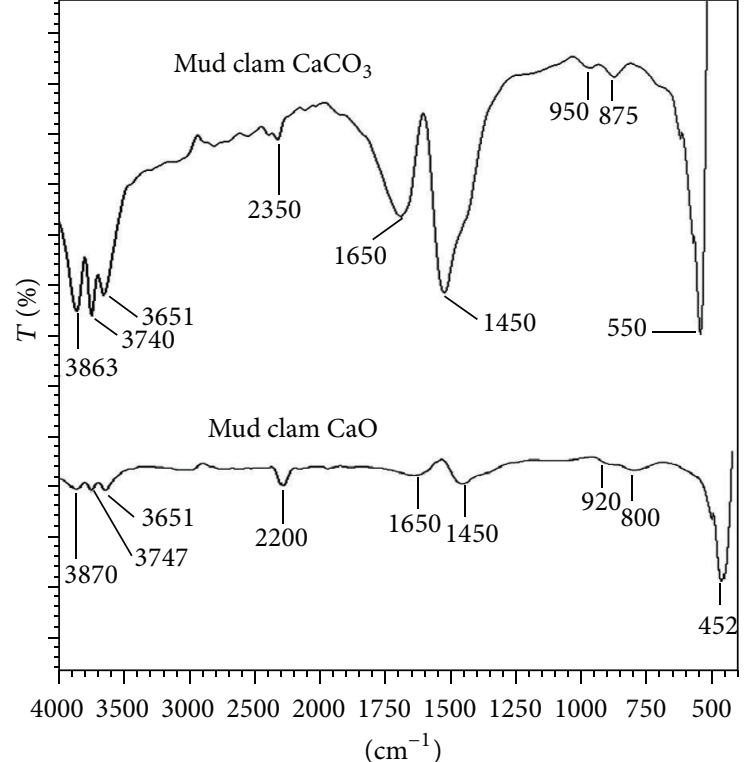

FIGURE 1: IR spectrum of mud clam calcium carbonate $\left(\mathrm{CaCO}_{3}\right)$ and calcium oxide $(\mathrm{CaO})$.

The parameters considered for transesterification study include the molar ratio of oil to methanol, catalyst concentration, reaction temperature, and reaction time. The optimum parameters were determined for the highest yield of the biodiesel. The molar ratio of oil to methanol used was $1: 10$ to $1: 18$. Catalyst concentration of $0.5 \%$ to $7 \% \mathrm{w} / \mathrm{w}$ (relative to oil weight), reaction temperature of $50^{\circ} \mathrm{C}$ to $70^{\circ} \mathrm{C}$, and reaction time of $1 / 2$ hour to 3 hours were used.

The optimum parameters which give the highest yield of biodiesel were determined. The percentage conversion of biodiesel was calculated by using the formula: biodiesel conversion yield $(\%)=($ experimental yield $) /($ theoretical yield $) \times$ $100 \%$. The catalyst performance of commercial calcium oxide and mud clam calcium oxide on transesterification of castor oil was compared using the optimum parameters of transesterification.

The reusability of the mud clam shell synthesized catalyst was examined for 5 cycles under the optimum condition: oilto-methanol molar ratio of $14: 1,3 \mathrm{wt} . \%$ catalysts (based on oil weight), a reaction temperature of $60^{\circ} \mathrm{C}$, and a reaction time of 2 hours. After each cycle, the used catalyst was separated from the reaction mixture by centrifugation and washed with n-hexane to remove any impurities. Next, the used catalyst dried and recalcined at $900^{\circ} \mathrm{C}$ for reutilization.

\section{Results and Discussion}

3.1. FT-IR Analysis of Heterogeneous Catalyst. Figure 1 shows the infrared spectrum of calcium carbonate $\left(\mathrm{CaCO}_{3}\right)$ and synthesized calcium oxide $(\mathrm{CaO})$ from mud clam shell. A sharp peak can be seen at $1450 \mathrm{~cm}^{-1}$ of mud clam calcium carbonate. The absorption peaks correspond to $\mathrm{C}-\mathrm{O}$ symmetrical stretching vibration of carbonates [17]. The absorption peaks at $1650 \mathrm{~cm}^{-1}$ and $2350 \mathrm{~cm}^{-1}$ correspond to $\mathrm{C}=\mathrm{O}$ stretching vibration of carbonates. The two weak peaks at $950 \mathrm{~cm}^{-1}$ and $875 \mathrm{~cm}^{-1}$ correspond to the out-of-plane bending vibration of $\mathrm{C}-\mathrm{O}$ bonds of carbonates.

Upon calcination, the calcium carbonate was thermally decomposed into calcium oxide and loses carbonate. Thus, this leads to the decrease of characteristics peaks of carbonates on the IR spectrum of the synthesized calcium oxide. The reduced intensity of absorption band which corresponds to carbonates can be seen at $2200 \mathrm{~cm}^{-1}, 1650 \mathrm{~cm}^{-1}, 1450 \mathrm{~cm}^{-1}$, $920 \mathrm{~cm}^{-1}$, and $800 \mathrm{~cm}^{-1}$ on the IR spectrum of calcium oxide from mud clam shell [18].

A sharp peak around $500 \mathrm{~cm}^{-1}$ of the infrared spectrum corresponds to functional group $\mathrm{Ca}-\mathrm{O}$ from calcium carbonates. The $\mathrm{Ca}-\mathrm{O}$ peak intensity reduced as calcium carbonate was decomposed to calcium oxide [18]. The absorption band in the range of $3651-3870 \mathrm{~cm}^{-1}$ on the infrared spectrum corresponds to hydroxyl group. The absorption peak of hydroxyl group is normally ascribed to the presence of calcium hydroxide. The existence of hydroxyl group resulted from absorption of atmospheric moisture during FT-IR analysis which subsequently formed calcium hydroxide. This phenomenon was common due to the high hydrophilicity nature of the compound [19].

3.2. Surface Morphology of Heterogeneous Catalyst. The SEM images in Figure 2 show the surface morphology of calcium oxide calcined from mud clam shell and the commercial calcium oxide. From Figure 2, it can be seen that natural mud clam $\mathrm{CaCO}_{3}$, Figure 2(a), is comprised of typical layered architecture [20]. The microstructure of the shell has changed from layered architecture to the porous structure after calcinations, Figure 2(b).

Calcium oxide synthesized from mud clam shell shows smaller particles compared to the uncalcined mud clam shell and arranged in the form of aggregates. The smaller size of the grains and aggregates of mud clam calcium oxide could provide a higher specific surface area [21]. These results were tallied with the particle size distributions of the both types of calcium oxides that will be discussed later in detail.

The commercial calcium oxide showed a porous structure with different shape of particles compared to the calcium oxide from mud clam shell. This different particle shapes can be explained by the different precursors of which the calcium oxide was synthesized. The different raw material used to synthesize calcium oxide may result in different features despite having a comparable gross chemical composition. The feature of catalyst should be correlated with the precursor type [22].

3.3. Catalyst Particle Size Distribution Analysis. Figures 3 and 4 show the particle size distribution of calcium oxide from the mud clam shell and the commercial calcium oxide. Calcium oxide from the mud clam shell shows a monomodal particle size distribution in a size range of 0.04 to $60 \mu \mathrm{m}$. A large fraction of the powder particle size falls within a range of $20-40 \mu \mathrm{m}$. The average particle diameter was $15.67 \mu \mathrm{m}$. The commercial calcium oxide shows a bimodal particle size distribution with a wider size range of 0.04 to $250 \mu \mathrm{m}$. The highest peak of the bimodal size distribution ranges from 


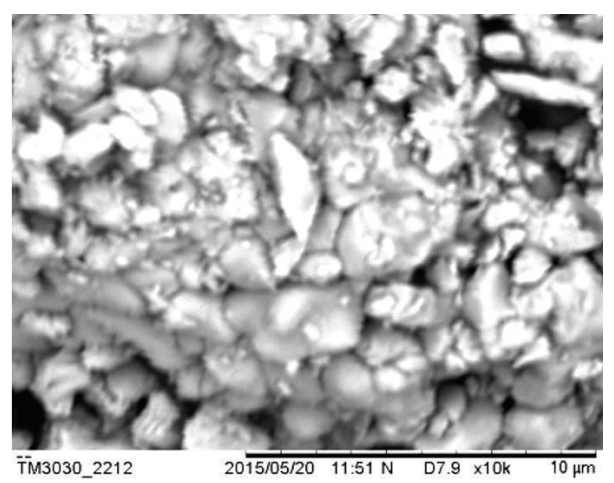

(a) Mud clam shell $\left(\mathrm{CaCO}_{3}\right)$

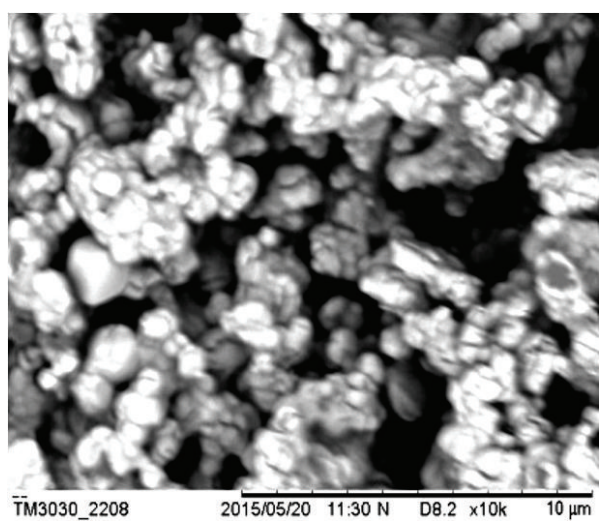

(b) Mud clam shell $\mathrm{CaO}$

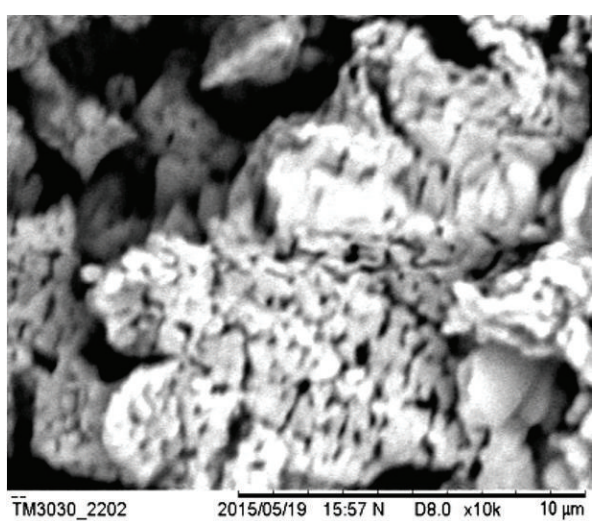

(c) Commercial $\mathrm{CaO}$

FIGURE 2: SEM images of heterogeneous catalyst and its raw material.

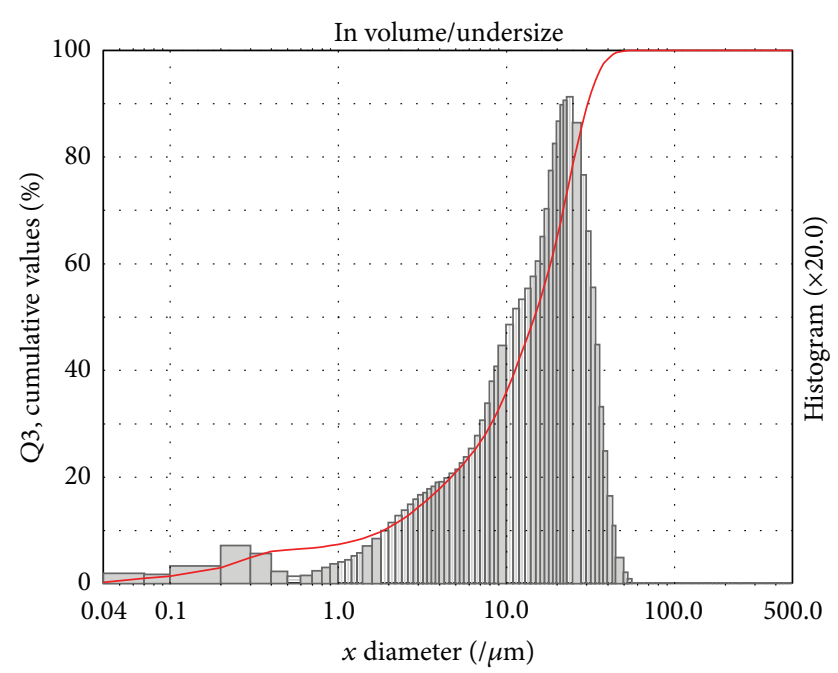

Figure 3: Particle size distribution of calcium oxide from mud clam shell.

50 to $100 \mu \mathrm{m}$ while the minor peak ranges from 2 to $10 \mu \mathrm{m}$. The average particle diameter reported was $41.79 \mu \mathrm{m}$.

The calcium oxide from mud clam shell shows a lower value of average particle diameter compared to the commercial calcium oxide thus having a smaller particle size.

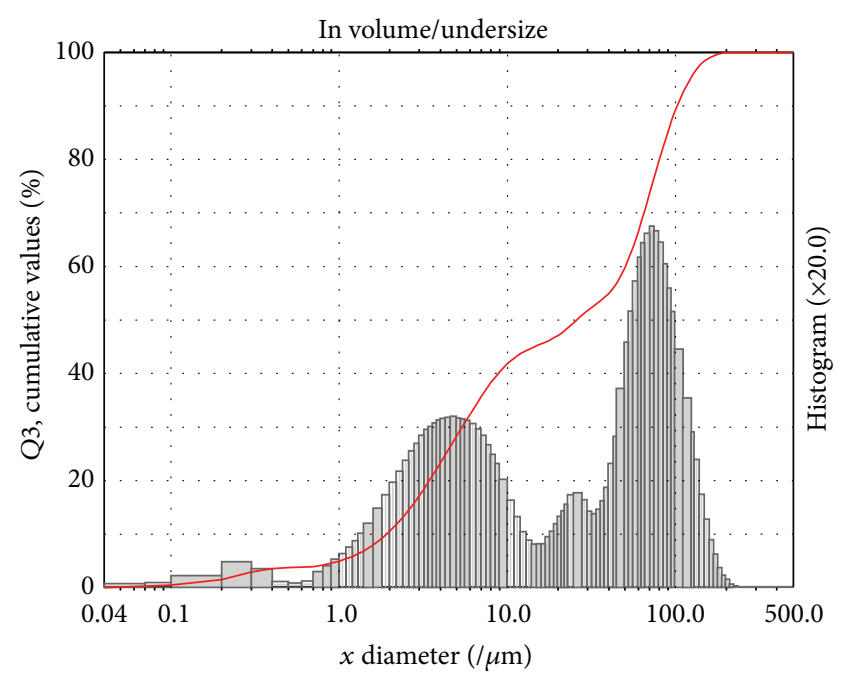

Figure 4: Particle size distribution of commercial calcium oxide.

The smaller particle size provides a higher surface area. The higher surface area of the catalyst would promote greater chance of collisions between the reactants and the catalyst, thus increasing the rate of transesterification reaction [23]. The bimodal distribution size of commercial calcium oxide 
TABLE 2: Catalyst BET result.

\begin{tabular}{lccc}
\hline Catalyst & $\begin{array}{c}\text { BET surface } \\
\text { area }\left(\mathrm{m}^{2} / \mathrm{g}\right)\end{array}$ & $\begin{array}{c}\text { Pore volume } \\
\left(\mathrm{cm}^{3} / \mathrm{g}\right)\end{array}$ & $\begin{array}{c}\text { Average pore } \\
\text { radius }(\AA)\end{array}$ \\
\hline $\begin{array}{l}\text { Commercial } \mathrm{CaO} \\
\begin{array}{l}\text { Mud clam shell } \\
\mathrm{CaO}\end{array}\end{array}$ & 62.91 & 0.097 & 36.3 \\
\hline
\end{tabular}

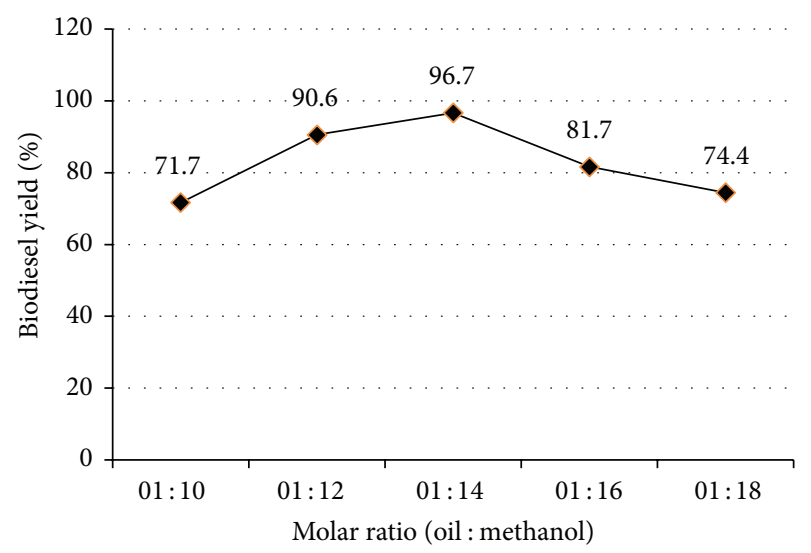

FIgURE 5: Molar ratio of oil to methanol versus biodiesel yield (\%).

could be explained by the presence of the small and micronanosized particles along with the large agglomerates as reported by Tan et al. [19].

3.4. Physical Properties of Heterogeneous Catalyst. The physical properties of the heterogeneous catalyst were presented in Table 2. The calcium oxide calcined from mud clam shell shows higher surface area of $68.57 \mathrm{~m}^{2} / \mathrm{g}$ as compared with the commercial calcium oxide that had a surface area of $62.91 \mathrm{~m}^{2} / \mathrm{g}$. The high surface area provides more active sites for the catalyzed transesterification reaction of triglycerides [24].

The pore radius and pore volume are vital in exhibiting the catalytic efficiency [22]. Calcium oxide from the mud clam shell also relatively had a higher average pore radius of $46.4 \AA$ and pore volume of $0.1 \mathrm{~cm}^{3} / \mathrm{g}$ compared to that of commercial calcium oxide which had an average pore radius of $36.3 \AA$ and pore volume of $0.097 \mathrm{~cm}^{3} / \mathrm{g}$. Thus, calcium oxide from mud clam shell with higher pore size and pore volume possesses higher catalytic efficiency compared to the commercial $\mathrm{CaO}$. The average pore radius of both calcium oxides was in the range of 3-5 nm. Thus, the calcium oxides can be classified as mesoporous material as their average pore diameter is between 2 and $50 \mathrm{~nm}$ [19].

3.5. Effect of Molar Ratio of Oil to Methanol on Biodiesel Yield. The experimental results were illustrated in Figure 5 indicating that the molar ratio of methanol to oil has a significant impact on the biodiesel yield. The biodiesel yield was increased with the molar ratio. 96.7\% yield was reported at 1:14 molar ratio of oil to the methanol. The excess of methanol is necessary because it can increase the rate of

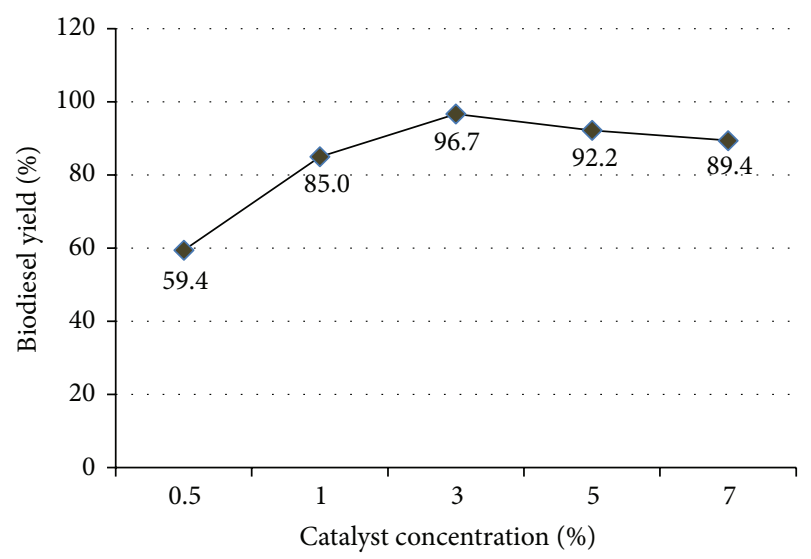

FIGURE 6: Catalyst concentration (\%) versus biodiesel yield (\%).

methanolysis. The high amount of methanol promoted the formation of methoxy species on the $\mathrm{CaO}$ surface, leading to a shift in the equilibrium towards forward direction, thus increasing the rate of biodiesel conversion [21]. However, the yield was slightly reduced when the ratio of oil to methanol was higher than $14: 1$. The biodiesel yield was only $74.4 \%$ at 1:18 oil-to-methanol molar ratio.

Further increase in oil-to-methanol ratio after optimal ratio of $1: 14$ would lead to a reduction of the biodiesel yield. This is due to excessive methanol beyond the optimal point which does not promote the reaction. The glycerol which is a by-product of the reaction would largely dissolve in the excessive methanol and subsequently inhibit the reaction of methanol to reactants and catalyst, thus interfering with the separation of glycerine, which in turn lowers the conversion by shifting the equilibrium in the reverse direction [25].

3.6. Effect of Catalyst Concentration on Biodiesel Yield. Catalyst concentration plays an important role in optimizing the yield of transesterification reaction. From Figure 6, it can be seen that biodiesel yield increases with the increase of catalyst concentration from $0.5 \% \mathrm{w} / \mathrm{w}$ to $3 \% \mathrm{w} / \mathrm{w}$ and also the yield was slightly decreased with further increase of catalyst concentration. The optimal catalyst concentration was determined to be $3 \% \mathrm{w} / \mathrm{w}$ of $\mathrm{CaO}$ catalyst with a biodiesel yield of $96.7 \%$. The excess catalyst has slightly reduced the biodiesel yield due to soap formation in the presence of high amount of catalyst. Further, this excess amount of catalyst increases the viscosity of reactants which also results in lowering the biodiesel yield as reported by Yang et al. [26]. The transesterification is not solely catalyzed by the basic sites generated on the surface of $\mathrm{CaO}$ catalyst but also the soluble substance leached away from $\mathrm{CaO}$ catalyst [27].

3.7. Effect of Reaction Temperature on Biodiesel Yield. Figure 7 shows the biodiesel yield from transesterification of castor oil at different reaction temperature from $50^{\circ} \mathrm{C}$ to $70^{\circ} \mathrm{C}$. The biodiesel yield increases with the reaction temperature until an optimal point of $60^{\circ} \mathrm{C}$ with a biodiesel yield of $96.7 \%$. Beyond this, the yield was decreased abruptly to $68.3 \%$ at $70^{\circ} \mathrm{C}$. Initially, some thermal energy was needed 


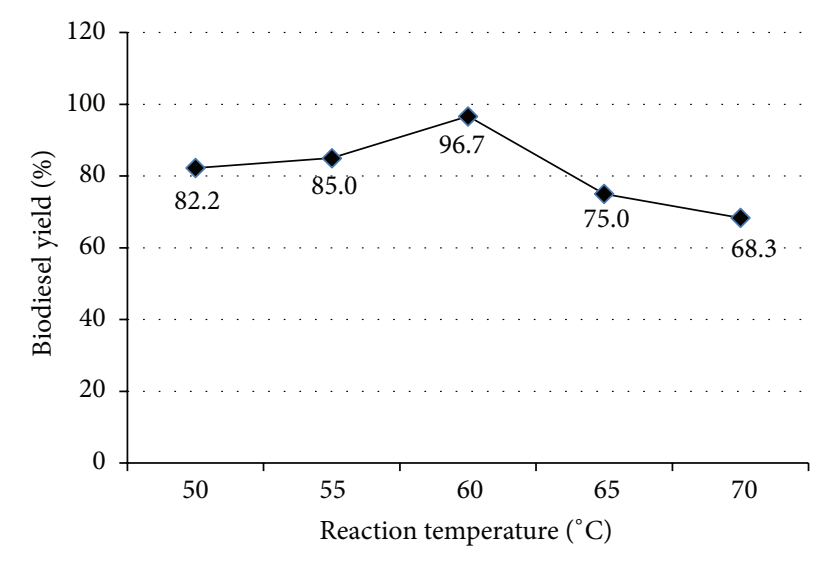

FIGURE 7: Reaction temperature $\left({ }^{\circ} \mathrm{C}\right)$ versus biodiesel yield (\%).

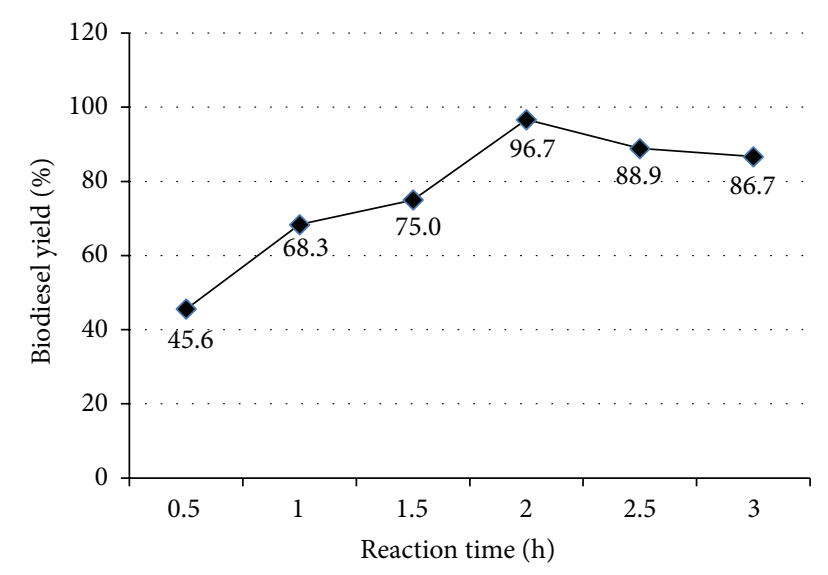

FIgURE 8: Reaction time (h) versus biodiesel yield (\%).

for the transesterification as the reaction was endothermic [28]. Since the reaction mixture constitutes a three-phase system (oil-methanol-catalyst), the thermal energy was sufficiently needed to overcome the diffusion resistance between different phases [29]. However, the high temperatures are not preferred. As the temperature increases and reaches the boiling point of methanol, the methanol will quickly vaporize and form a large number of bubbles, which inhibits the reaction on the two-phase interface and thus decreases the biodiesel yield [30].

3.8. Effect of Reaction Time on Biodiesel Yield. Figure 8 shows the biodiesel yield for the transesterification of castor oil in different reaction time from 0.5 hour to 3 hours. In the initial stages of the transesterification reaction, production of biodiesel was rapid until the reaction has reached equilibrium. Beyond the optimal point, the reaction starts to reverse in backward direction towards reactants. This phenomenon occurred due to the reversibility of transesterification reaction $[28,31]$. CaO catalyst has a tendency to adsorb products when reactant was lack [32]. Therefore too long reaction time also reduces the biodiesel yield as the $\mathrm{CaO}$ catalyst can absorb the product. Hence it is important to identify the optimum reaction time for the transesterification reaction. In this case,
TABLE 3: Biodiesel yield of calcium oxide catalyzed transesterification using optimum reaction condition.

\begin{tabular}{lc}
\hline Catalyst & Biodiesel yield (\%) \\
\hline Mud clam shell $\mathrm{CaO}$ & 96.7 \\
Commercial $\mathrm{CaO}$ & 93 \\
\hline
\end{tabular}

the optimum reaction time was 2 hours with a biodiesel yield of $96.7 \%$.

3.9. Comparison of Biodiesel Yield from Different Heterogeneous Catalyst. Table 3 shows the biodiesel yield of calcium oxide catalyzed transesterification of castor oil using optimum reaction condition. From the experiment, it was determined that the optimum parameters for transesterification of castor oil with calcium oxide from mud clam shell were $1: 14$ (oil: methanol), $3 \% \mathrm{w} / \mathrm{w}$ catalyst concentration, $60^{\circ} \mathrm{C}$ reaction temperature, and 2-hour reaction time. The optimum parameters for transesterification of castor oil give the highest biodiesel yield of $96.7 \%$. The optimum parameters were then used for transesterification of castor oil using commercial calcium oxide as a catalyst and the biodiesel yield achieved was $93 \%$.

The result showed that the calcium oxide synthesized from mud clam shell is more reactive than the commercial one. This can be explained by the different precursor of which the calcium oxide was synthesized. The different raw material used to synthesize calcium oxide may result in different feature despite comparable gross chemical composition of the compounds.

The feature of catalyst should be correlated with the precursor type [22]. Calcium oxide was calcined from calcium carbonate. Calcium carbonate can be found abundantly in nature as limestone and various species of sea shells.

The biodiesel yield from transesterification of castor oil in this study was higher as compared to other reported studies. As reported by Forero [9], a biodiesel yield of $91.17 \%$ was noted for transesterification of castor oil using calcium oxide derived from mussel shell. The transesterification of castor oil using alkaline catalyst $(\mathrm{KOH})$ gives a maximum yield of 95.8\% [7]. The transeterification of castor oil catalyzed by double-metal cyanide complexes yielded 78.3\% [33].

3.10. Reusability of Mud Clam Shell Derived Catalyst. Figure 9 showed the biodiesel yield of mud clam shell synthesized calcium oxide catalyzed transesterification of castor oil in 5 cycles. The results show that the biodiesel yield reduced slightly even after 5 cycles with a decrement of $12.2 \%$. The biodiesel yield after 5 times of reusing the catalyst was 84.5\%. The biodiesel yield from commercial calcium oxide catalyzed transesterification shows the same trend with slight decrement after 5 cycles of transesterification with the reused catalyst. The maximum decrement of $10.7 \%$ was observed after 5 runs using commercial calcium oxide. The biodiesel yield was $82.3 \%$ after 5 times of reusing the catalyst.

The reduced catalyst activity was due to the agglomeration of the catalyst particles after being reused in transesterification. The size of the agglomeration of the catalyst 


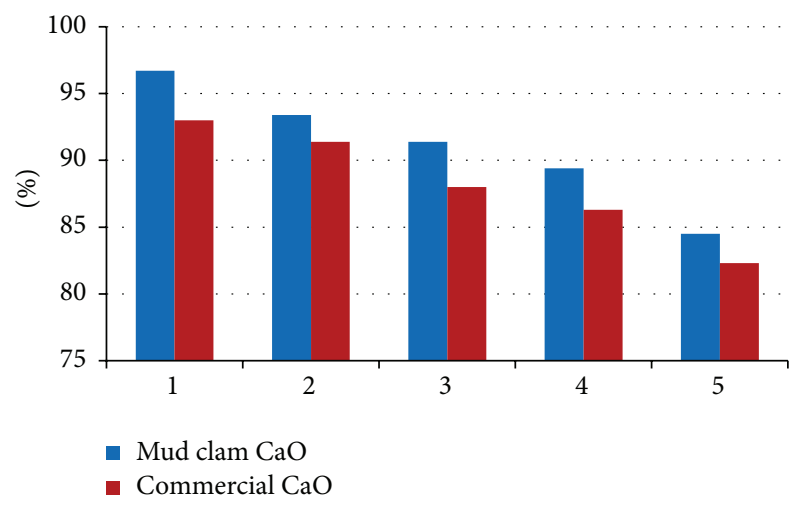

FIGURE 9: Effect of reusability of catalyst on biodiesel yield.

particles was getting bigger as the number of transesterification cycles increases. Thus, the biodiesel yield decreases when the number of cycles increases. The calcium oxide from mud clam shell shows high potential of reusability for transesterification reaction for biodiesel production with only small loss of catalytic activity. The stability and reactivity of the synthesized calcium oxide from mud clam shell were better than the commercial calcium oxide with a higher biodiesel yield for 5 cycles of transesterification [19].

\section{Conclusion}

In conclusion, the calcium oxide synthesized from mud clam shell shows good catalytic performance and physicochemical properties as a heterogeneous catalyst for biodiesel production. The optimum parameters of calcium oxide catalyzed transesterification of castor oil were determined as 1:14 oil-to-methanol molar ratio, $3 \% \mathrm{w} / \mathrm{w}$ catalyst concentration, $60^{\circ} \mathrm{C}$ reaction temperature, and 2 -hour reaction time. Reusablity test shows that the synthesized calcium oxide from mud clam shell is reusable up to 5 times.

\section{Competing Interests}

The authors declare that they have no competing interests.

\section{Acknowledgments}

This study was supported by Faculty of Engineering, University Malaysia Sarawak, Malaysia.

\section{References}

[1] R. U. Owolabi, A. L. Adejumo, and A. F. Aderibigbe, "Biodiesel: fuel for the future," International Journal of Energy Engineering, vol. 2, no. 5, pp. 223-231, 2012.

[2] B. R. Moser, "Biodiesel production, properties and feedstocks," In Vitro Cellular \& Developmental Biology-Plant, vol. 45, pp. 229-266, 2009.

[3] D.-W. Lee, Y.-M. Park, and K.-Y. Lee, "Heterogeneous base catalysts for transesterification in biodiesel synthesis," Catalysis Surveys from Asia, vol. 13, no. 2, pp. 63-77, 2009.
[4] J. Boro, A. J. Thakur, and D. Deka, "Solid oxide derived from waste shells of Turbonilla striatula as a renewable catalyst for biodiesel production," Fuel Processing Technology, vol. 92, no. 10, pp. 2061-2067, 2011.

[5] Y. B. Cho and G. Seo, "High activity of acid-treated quail eggshell catalysts in the transesterification of palm oil with methanol," Bioresource Technology, vol. 101, no. 22, pp. 85158519, 2010.

[6] M. Kouzu, T. Kasuno, M. Tajika, Y. Sugimoto, S. Yamanaka, and J. Hidaka, "Calcium oxide as a solid base catalyst for transesterification of soybean oil and its application to biodiesel production," Fuel, vol. 87, no. 12, pp. 2798-2806, 2008.

[7] M. M. Conceição, R. A. Candeia, F. C. Silva, A. F. Bezerra, V. J. Fernandes Jr., and A. G. Souza, "Thermoanalytical characterization of castor oil biodiesel," Renewable and Sustainable Energy Reviews, vol. 11, no. 5, pp. 964-975, 2007.

[8] K. Ramezani, S. Rowshanzamir, and M. H. Eikani, "Castor oil transesterification reaction: a kinetic study and optimization of parameters," Energy, vol. 35, no. 10, pp. 4142-4148, 2010.

[9] C. L. B. Forero, Biodiesel from Castor Oil: A Promising Fuel for Cold weather, Department of Hydraulic, Fluids and Thermal Sciences, Fransisco de Paula Santander University, 2004.

[10] N. L. Panwar, H. Y. Shrirame, and B. R. Bamniya, " $\mathrm{CO}_{2}$ mitigation potential from biodiesel of castor seed oil in Indian context," Clean Technologies and Environmental Policy, vol. 12, no. 5, pp. 579-582, 2010.

[11] G.-T. Jeong and D.-H. Park, "Optimization of biodiesel production from castor oil using response surface methodology," Applied Biochemistry and Biotechnology, vol. 156, no. 1, pp. 1-11, 2009.

[12] S. Nurdin, N. A. Rosnan, N. S. Ghazali, J. Gimbun, A. H. Nour, and S. F. Haron, "Economical biodiesel fuel synthesis from castor oil using mussel shell-base catalyst (MS-BC)," Energy Procedia, vol. 79, pp. 576-583, 2015.

[13] M. Sánchez-Cantú, L. M. Pérez-Díaz, I. Pala-Rosas et al., "Hydrated lime as an effective heterogeneous catalyst for the transesterification of castor oil and methanol," Fuel, vol. 110, pp. 54-62, 2013.

[14] U. G. Akpan, A. Jimoh, and A. D. Mohammed, Extraction, Characterization and Modification of Castor Seed Oil, 2013, http://ljs.academicdirect.org/A08/43_52.htm.

[15] H. J. Berchmans and S. Hirata, "Biodiesel production from crude Jatropha curcas L. seed oil with a high content of free fatty acids," Bioresource Technology, vol. 99, no. 6, pp. 1716-1721, 2008.

[16] B. Yoosuk, P. Udomsap, B. Puttasawat, and P. Krasae, "Improving transesterification acitvity of $\mathrm{CaO}$ with hydration technique," Bioresource Technology, vol. 101, no. 10, pp. 3784-3786, 2010.

[17] J. García, T. López, M. Álvarez, D. H. Aguilar, and P. Quintana, "Spectroscopic, structural and textural properties of $\mathrm{CaO}$ and $\mathrm{CaO}-\mathrm{SiO} 2$ materials synthesized by sol-gel with different acid catalysts," Journal of Non-Crystalline Solids, vol. 354, no. 2-9, pp. 729-732, 2008.

[18] M. Galván-Ruiz, J. Hernández, L. Baños, J. Noriega-Montes, E. Mario, and G. Rodríguez, "Characterization of calcium carbonate, calcium oxide, and calcium hydroxide as starting point to the improvement of lime for their use in construction," Journal of Materials in Civil Engineering, vol. 21, no. 11, pp. 694-698, 2009.

[19] Y. H. Tan, M. O. Abdullah, C. Nolasco-Hipolito, and Y. H. Taufiq-Yap, "Waste ostrich- and chicken-eggshells as heterogeneous base catalyst for biodiesel production from used cooking 
oil: catalyst characterization and biodiesel yield performance," Applied Energy, vol. 160, pp. 58-70, 2015.

[20] J. Geist, K. Auerswald, and A. Boom, "Stable carbon isotopes in freshwater mussel shells: environmental record or marker for metabolic activity?" Geochimica et Cosmochimica Acta, vol. 69, no. 14, pp. 3545-3554, 2005.

[21] A. Buasri, N. Chaiyut, V. Loryuenyong, P. Worawanitchaphong, and S. Trongyong, "Calcium oxide derived from waste shells of mussel, cockle, and scallop as the heterogeneous catalyst for biodiesel production," The Scientific World Journal, vol. 2013, Article ID 460923, 7 pages, 2013.

[22] R. B. Ljupković, N. S. Radulović, A. L. Bojić, A. R. Zarubica, R. D. Mićić, and M. D. Tomić, "Significance of the structural properties of $\mathrm{CaO}$ catalyst in the production of biodiesel: an effect on the reduction of greenhouse gases emission," Hemijska Industrija, vol. 68, no. 4, pp. 399-412, 2014.

[23] N. S. El-Gendy, A. Hamdy, and S. S. Abu Amr, "An investigation of biodiesel production from wastes of seafood restaurants," International Journal of Biomaterials, vol. 2014, Article ID 609624, 17 pages, 2014.

[24] A. A. Refaat, "Biodiesel production using solid metal oxide catalysts," International Journal of Environmental Science and Technology, vol. 8, no. 1, pp. 203-221, 2011.

[25] B. P. Lim, G. P. Maniam, and S. A. Hamid, "Biodiesel from adsorbed waste oil on spent bleaching clay using $\mathrm{CaO}$ as a heterogeneous catalyst," European Journal of Scientific Research, vol. 33, no. 2, pp. 347-357, 2009.

[26] F.-X. Yang, Y.-Q. Su, X.-H. Li, Q. Zhang, and R.-C. Sun, "Preparation of biodiesel from Idesia polycarpa var. vestita fruit oil," Industrial Crops and Products, vol. 29, no. 2-3, pp. 622-628, 2009.

[27] M. L. Granados, M. D. Z. Poves, D. M. Alonso et al., "Biodiesel from sunflower oil by using activated calcium oxide," Applied Catalysis B: Environmental, vol. 73, no. 3, pp. 317-326, 2007.

[28] C. Samart, P. Sreetongkittikul, and C. Sookman, "Heterogeneous catalysis of transesterification of soybean oil using KI/ mesoporous silica," Fuel Processing Technology, vol. 90, no. 7-8, pp. 922-925, 2009.

[29] X. Liu, H. He, Y. Wang, S. Zhu, and X. Piao, "Transesterification of soybean oil to biodiesel using $\mathrm{CaO}$ as a solid base catalyst," Fuel, vol. 87, no. 2, pp. 216-221, 2008.

[30] T. Long, Y. Deng, S. Gan, and J. Chen, "Application of choline chloride.xZnCl2 ionic liquids for preparation of biodiesel," Chinese Journal of Chemical Engineering, vol. 18, no. 2, pp. 322327, 2010.

[31] A. Santana, J. Maçaira, and M. A. Larrayoz, "Continuous production of biodiesel using supercritical fluids: a comparative study between methanol and ethanol," Fuel Processing Technology, vol. 102, pp. 110-115, 2012.

[32] Y. H. Taufiq-Yap, H. V. Lee, M. Z. Hussein, and R. Yunus, "Calcium-based mixed oxide catalysts for methanolysis of Jatropha curcas oil to biodiesel," Biomass and Bioenergy, vol. 35, no. 2, pp. 827-834, 2011.

[33] P. S. Sreeprasanth, R. Srivastava, D. Srinivas, and P. Ratnasamy, "Hydrophobic, solid acid catalysts for production of biofuels and lubricants," Applied Catalysis A: General, vol. 314, no. 2, pp. 148-159, 2006.

[34] J. Salimon, M. N. D. Azleema, A. T. Nazrizawati, M. Y. M. Firdaus, and A. Noraishah, "Fatty acid composition and physicochemical properties of malaysian castor bean ricinus communis L. Seed oil," Sains Malaysiana, vol. 39, pp. 761-764, 2010. 

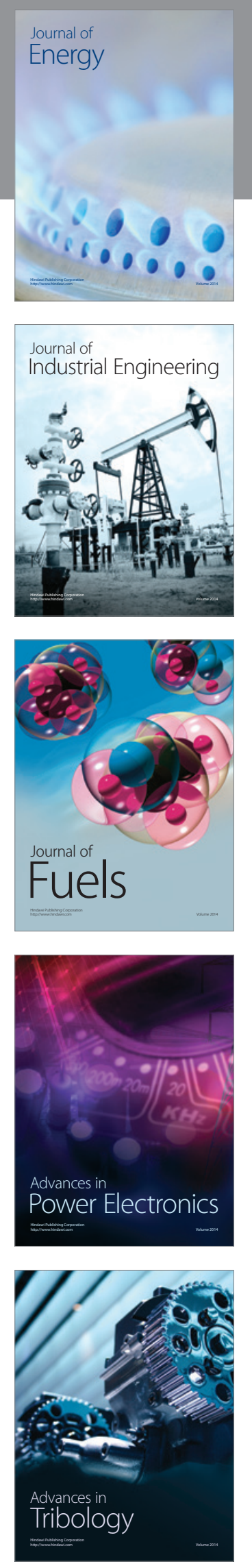
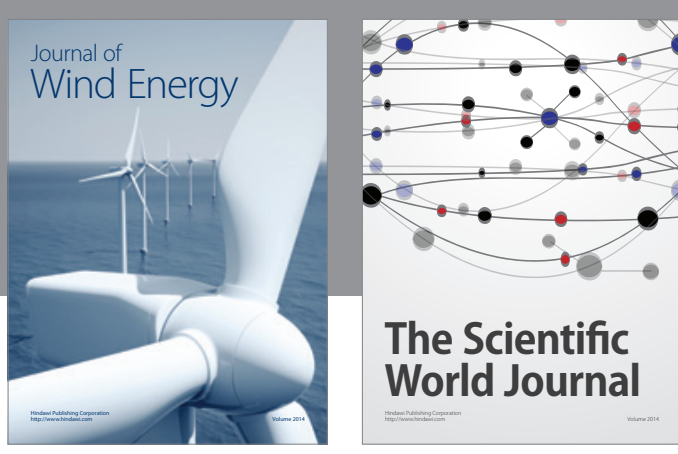

The Scientific World Journal
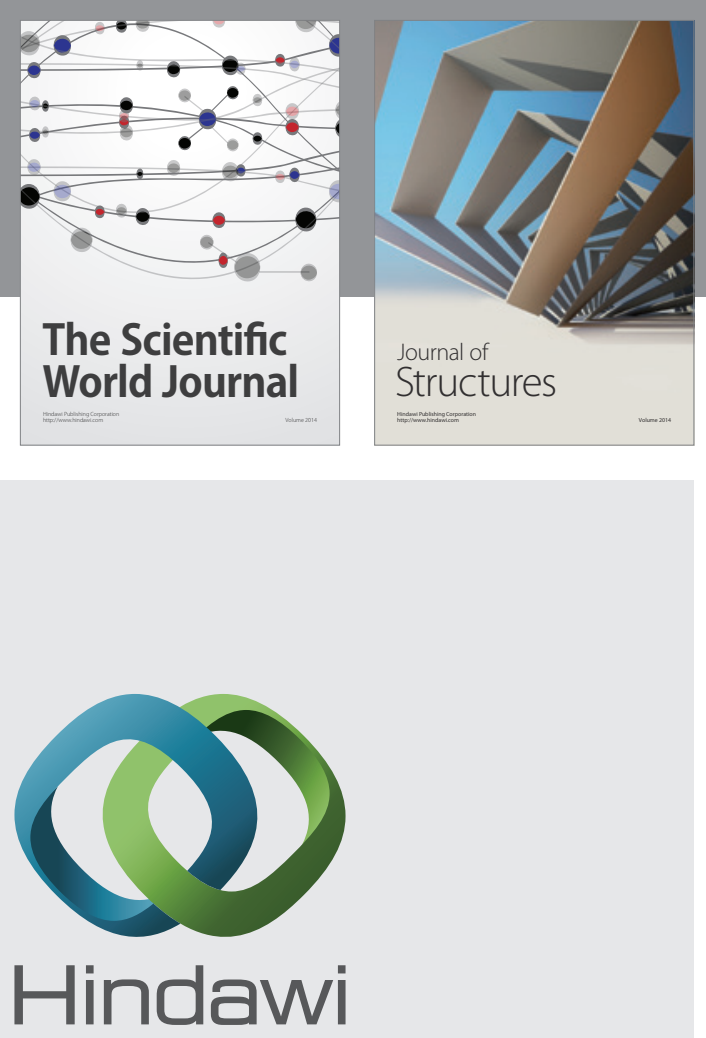

Submit your manuscripts at

http://www.hindawi.com
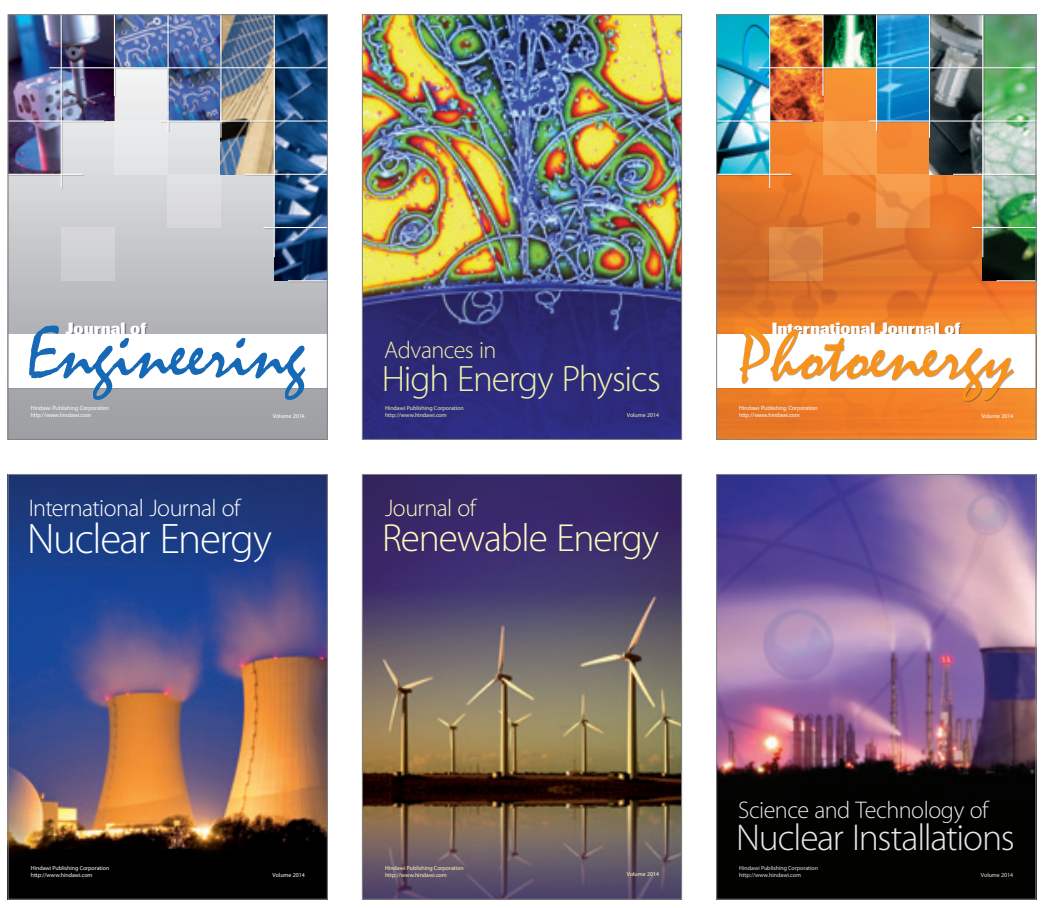
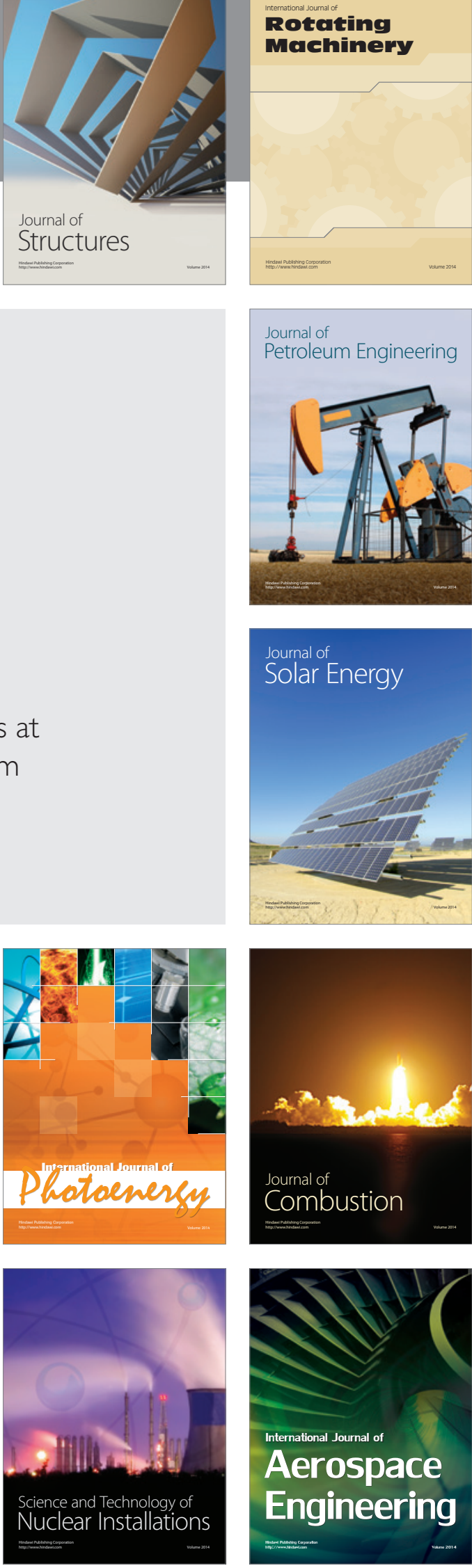